\title{
Analysis on the Implementation of Home-Based Care Service Policy in Changchun City - Based on Policy Implementation Process Model of Smith
}

\author{
Jianmei Chen ${ }^{1}$, Zirong Liu $^{2, *}$ \\ ${ }^{1,2}$ School of Harbin University of Commerce of Finance and public management, Harbin, Heilongjiang, 150028, China \\ *Corresponding author. Email: 13331566567@163.com
}

\begin{abstract}
Population aging is a key issue that cannot be ignored in China's accelerated socialist modernization. The paper uses Smith's policy implementation process model to analyse the implementation of Changchun's home-based care service policy and finds out four problems in the policy implementation process: there are few supporting policies and service organizations for home-based care, the participation of target groups is low, and the professionalism of executive staff needs to be improved. Based on this, it is suggested to optimize the policy in four aspects: improving the policy content, enhancing the implementation capacity of service institutions, mobilizing the enthusiasm of target groups, and improving the policy implementation environment.
\end{abstract}

Keywords: Home-based care services, policy implementation, the smith policy implementation process model, elderly

\section{INTRODUCTION}

With the improvement of social living standards, the demand of the elderly for old-age care is no longer limited to traditional care services, but towards the direction of diversification and specialization, thus home-based care emerges as the times require. In the United Kingdom, home-based care service appeared earlier and was influenced by the idea of "deinstitutionalization" at that time, which led to concepts of "care in the community" and "care by the community".[1] In the United States, the earliest known origins of home-based care services originated from "Kearsley Retirement Community", which is the first care community in the United States that mainly providing continuous care services for low-income seniors [2] In Sweden, the government has established a home care service system with comprehensive service items, mainly including personal hygiene, security alarm, nursing and other services [3]. Japan Government has not only established a special institution, but also a "care insurance system" through the power of non-profit organizations to provide home-based care services for the elderly [4]. In China, home-based care is a new model of care for the elderly. It not only realizes the convenience of elderly aging at home, reduces the pressure of children, but also satisfies the sense of belonging of elderly people to the family. Changchun, as one of the cities with high population aging in China, solving the aging problem is in the main position among many social issues, and since 2008, Changchun government has promulgated a series of policies for home-bsed care services.

\section{THEORETICAL FRAMEWORK}

\subsection{Smith Policy Implementation Process Model}

In this paper, we analyse the policy implementation process of Changchun's home-based care services in the context of Smith's policy implementation process model (Figure 1).In the Policy Implementation Process, Smith argues that after the implementation of public policy, a "tension" arises in society,[5] which may lead to violent protests, and measures are needed to ensure the successful implementation of the policy, and the tension also forms feedback to the policy, which may further support or hinder the policy system. The four factors that influence the successful implementation of public policy are: idealized policy, implementing organization, target group, and environment factors. The four factors complement each other, and each of them affects the effectiveness of policy implementation. 


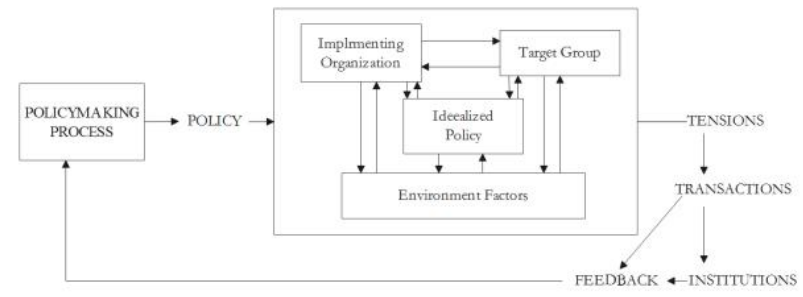

Figure 1 Smith policy implementation process model

\subsection{Analysis Framework of Home-cared Service Policy}

Pension policy is part of public policy. The implementation process of home-based care services policy has similarity with the public policy implementation process. Like public policy, home-based care services policy is also influenced by idealized policy, implementing organization, target group and environment factors. This paper constructs an analytical framework for the implementation of Changchun's elderly home-based care service policy based on Smith's policy implementation process model (Figure 2). The relationships among and within the above four parts are complementary, and even if one part is tense or uncoordinated, it will affect the efficiency of the implementation of Changchun homebased care service policy and cause the results of this policy implementation to fail to meet expectations.

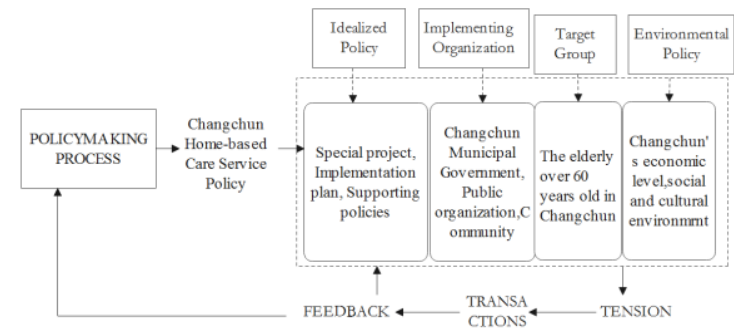

Figure 2 Analysis framework of Changchun home-based care service policy implementation

\section{IMPLEMENTATION PROCESS}

In 2008, the "Notice on the Implementation Plan of Homebased Care Service" was promulgated, which mainly made relevant requirements for the organizations and leading departments of home-based care service, so that the initial phase of the home-based care services could be better implemented in Changchun. In 2013, the Changchun Municipal Government issued the "Implementation Opinions on the Implementation of Changchun homebased care services ", which provides guidance on the development of home-based care services in Changchun, including the object, scope, content and methods. In 2016, Changchun Municipal Civil Affairs Bureau issued the
"Changchun home-based care service standard", which improved the Changchun home-based care service policy. It regulated the three major aspects of service subject standards, practitioner standards and service content standards in more detail and promoted the construction of the home-based care service system in Changchun City. In 2018, Changchun Municipal Civil Affairs Bureau issued "the Notice on Standardizing the Government's Purchase of Home-based Care Services", which made specific requirements for government departments to purchase home-based care services, with the aim of promoting the healthy, orderly and stable development of home-based care services.

The implementation body of Changchun's home-based care service policy consists of Changchun Municipal Government, organizations and employees engaged in home-based care service. The target group consists of Changchun's senior citizens over 60 years old. Although the economic and social factors of Changchun City have determined that most elderly people still choose traditional family retirement as the main way of retirement, with the encouragement and promotion of various policies in recent years, Changchun City has achieved significant development of home-based care service. The number of home-based care service centers is increasing, the scope of service is gradually expanding, the home-based care service is increasingly standardized, and the service forms are constantly innovating, which has initially shaped the basic pattern of home care services in Changchun.

\section{RESTRICTIVE FACTORS}

\subsection{Idealized Policy}

The current policies issued for home-based care in Changchun City focus more on the principle issues, and the practical operation issues are less considered in the policies. On the one hand, document does not give a detailed description of the service specification. Therefore, in the actual process of home-based care service, most implementing organization are relying on the traditional experience and consciousness of the elderly care service. On the other hand, in the home-based care service policy, there is no perfect supervision and management mechanism for the executive agencies and personnel, relying only on the consciousness of the implementing organization and the target group to enjoy the service.

\subsection{Implementing Organization}

The quality of service personnel needs to be improved in the implementing organization. Due to the special nature of elderly services, the service personnel should not only have basic medical knowledge but also need to master skilled nursing skills. The service personnel now engaged in home-based care in Changchun are mostly unemployed 
or urban workers who are old, have low education level and have not received professional medical and nursing training, and lack of doctors and nurses with professional experience. In addition, the work of serving the elderly is intense and complex, and the positions are responsible and require sufficient care and patience, and the compensation is relatively small, so the service staff is insufficient and relatively large mobility.

\subsection{Target Group}

At present, Changchun City has a very limited number of people for home-based care services. On the one hand, home-based care service is not the "mainstream" for residents to choose care services. Many elderly people and their children do not understand home-based care service and confuse it with family care. On the other hand, homebased care services have not been popularized to all the elderly groups who need services. Because some homebased care services are provided by profit-making enterprises purchased by the government, and most of the services they provide are paid services, which makes the elderly "flinch".

\subsection{Environmental Factors}

At this stage, home-based care service centers are widely distributed in Changchun, but the number is relatively small. Although they are distributed in all districts of Changchun, the quantity does not meet the current market demand and does not form a systematic and comprehensive service pattern [6]. Therefore, home-based care service centers in Changchun are still in the construction period. Although the various departments of Changchun municipal government have attached great importance to the construction of home-based care service system, and the economic support for this aspect has gradually increased, the development of home-based care service at this stage is still in a state of low overall facilities level, and the government's financial investment in this aspect is far from enough.

\section{OPTIMIZATION PATH}

\subsection{Improve the Content of Home-based Care Service Policy}

Strengthen the completeness and operability of the policy system of home-based care services, and formulate corresponding policies for the evaluation and supervision system, and promote the improvement of the quality of home-based care services. It is possible to establish a longterm evaluation and supervision mechanism and a systematic and scientific evaluation index system for the executive agencies and personnel, and to restrain them with clear rules and regulations to strengthen the consciousness of service personnel, so as to promote the standardization of home-based care service centers in Changchun, and thus promote the improvement of homebased care service supply.

\subsection{Enhance the Executive Power of Home- based Care Policy Implementation Agencies}

In order to promote the "qualitative change" of homebased care service industry, it is necessary to improve the professional ability of home-based care service personnel. We can cooperate with hospitals and universities in Changchun to conduct lectures on professional knowledge and provide professional training on the skills, so as to promote the development of the elderly service personnel in the direction of professionalism .At the same time, organizing medical students in Changchun University to conduct social practice in the pension service center, which can not only guarantee the quality of pension service, but also solve the problem of insufficient volunteers.

\subsection{Mobilize the Enthusiasm of Target Groups}

Focus on strengthening the publicity of the concept of home-based care services and actively promote the transformation of the concept of elderly care. We can integrate the effective resources of all parties, give full play to the advantages of the media and network, publicize the concept and policies of home-based care on TV, radio and Internet platforms, and provide detailed descriptions of specific service items. In addition, we can also carry out offline publicity activities of home-based care services in the community, displaying the service items on site and allowing the elderly in the community to experience.

\subsection{Optimize the Implementation Environment of Home-based Care Policy}

Changchun government should increase the support of funding for home-based services. In this regard, some necessary measures can be implemented to broaden the source of funds for home-based care services, attract more social forces to invest. At the same time, combine the estimated cost of home care services in Changchun with the government's current revenue needs, make accounting and subsidies for different elderly service projects, and further adjust the scale of the fund budget, so as to guarantee the source of funds and realize the development of elderly care work. In this way, we can guarantee the funding source, realize the efficiency of senior care work, and gradually improve the standard of home-based care services. 


\section{CONCLUSION}

Through the analysis of the implementation process model of Smith's policy, four problems of Changchun homebased care service policy can be found: the policy system lacks completeness and operability; the implementation organization agency lacks professionalism, professionalism and professional ability need to be improved; the target group is small in scope and lacks understanding of the policy; the policy environment, economic environment and social environment need to be further activated. Therefore, we should continuously improve the policy system of home-based care service in Changchun, increase the financial investment in homebased care services in Changchun, strengthen the skill training of service personnel, and actively promote the policy of home-based care services, and bring more elderly people who need the service into the system.

\section{ACKNOWLEDGMENT}

This work was supported by Harbin University of Commerce Teaching Reform and teaching research project "research and practice of labor and social security specialty construction from the perspective of professional certification"(HSDJY202008).

\section{REFERENCES}

[1] Li Lei. Research on the current situation and improvement path of home-based care services in China: Based on the successful experience of Japan and Britain [J]. Journal of Changsha Civil Affairs Vocational Technology College, 2014, 21(02):9-12. (In Chinese)

[2] Zou Haiyan. Research on home-based care services in urban communities in China based on social work perspective [D]. Beijing Jiaotong University, 2016. (In Chinese)

[3] Zhang Xiangyun. The experience and revelation of foreign home care approach-Take the United States, Finland, Sweden and Japan as examples [J]. Special Economic Zone, 2013(10):49-50. (In Chinese)

[4] Wu Di. Non-profit organizations in home-based care services: Japan's experience and its inspiration in China [J]. Journal of Hubei Administrative College, 2015(01):43-48. (In Chinese)

[5] Thomas B Smith. "The Policy Implementation Process", Policy Sciences 1973, (4), pp.197-209.

[6] Mu Yanchun, Wu Xuemeng, LI Yuan, Cui Yueqin. Research on the development mode of home-based care services: Research Report on Home-based Care Service Centers in Changchun [J]. Welfare Research, 2019, 2(00):1-10. (In Chinese) 